association between youths' social positions in friendship networks and their smoking behaviors.

\section{Smoking in Adolescence}

Adolescents may not have a long window in which to experiment with smoking without developing a dependency, because nicotine addiction occurs early in the onset of smoking (Gervais, O'Loughlin, Meshefedjian, Bancej, \& Tremblay, 2006). Indeed, 20- 60\% of adolescent smokers are dependent on nicotine (Colby, Tiffany, Shirffman, \& Niaura, 2000), which may be why they are likely to become regular smokers in adulthood (Chassin, Presson, Rose, \& Sherman, 1996). In addition to the risk of rapid dependency, adolescent smoking is commonly accompanied by other risky behaviors, such as stealing, violence, and skipping school (e.g., Tucker, Martinez, Ellickson, \& Edelen, 2008) and poor academic performance (Bryant, Schulenberg, Bachman, O'Malley, \& Johnson, 2000). In the long term, adolescent smoking is associated with numerous health issues experienced as adults, such as cancer, heart disease, and premature death (Ezzati \& Lopez, 2000; Warren, Jones, Eriksen, $\&$ Asma, 2006). For all of these reasons, adolescent smoking is a significant public health concern.

\section{Network Position and Smoking}

This study focuses on three network positions: isolates, members, and liaisons. An isolate, in the strictest definition, is a person who is not connected to others within a network (Wasserman \& Faust, 1994). In contrast, members and liaisons are both connected to others in the social network. More specifically, members' connections are mostly with other members of the same group, whereas liaisons' connections are to two or more different groups within a social network (Richards \& Rice, 1981). The reasons why particular positions may be associated with smoking are outlined next; they revolve around stress, access, support, and social distancing.

\section{Stressful connections}

Members and liaisons may be more likely to smoke than isolates because of the stress of maintaining their relationships. Maintaining social relationships can be stressful (Buunk \& Hoorens, 1992), particularly in adolescence (Arnett, 1999; Hartup, 1989). Ikard, Green, \& Horn (1969) contended that some people cope with their stress and negative moods by smoking tobacco. In fact, studies (Nichter, Nichter, Vuckovic, Quintero, \& Ritenbaugh, 1997; Eiser, Walsh, \& Eiser, 1986) report that the most repeatedly cited reason adolescents give for smoking was to reduce stress and relax.

Relationship stress may take a different form for members and liaisons. Members may face the challenge of maintaining their popularity within their particular cohesive sub-group (Eder, 1985), and they may feel pressured to engage in risky behaviors, such as smoking, in order to keep their popularity within their group (Valente, Unger, \& Johnson, 2005). Popular girls were more likely to smoke than others in order to maintain their popularity (Michell, 1997; Michell \& Amos, 1997). In contrast, liaisons have more diverse social networks, which come with the potential stress of presenting themselves differently to each group in 
order to manage their impressions and reputations with the different groups (Goffman, 1959; Petronio, 2000).

\section{Exposure}

Liaisons may be more likely to smoke than members or isolates because they have greater exposure to people engaging in different behaviors, including smoking. People with more diverse social networks, such as liaisons, can more easily gain support, such as informational support (i.e., knowledge relevant to a situation) and tangible support (e.g., resources; Schaeffer, Coyne, \& Lazarus, 1981). Networks can provide knowledge and resources for healthy or unhealthy activities, such as smoking. Studies show that adolescents learn about smoking from their friends (Oetting \& Donnermeyer, 1998; Oetting,

Deffenbacher, \& Donnermeyer, 1998; Oetting \& Beauvais, 1986). Further, if adolescents are exposed to smokers and smoking through their networks, then they generally have a positive attitude toward it (Sutherland \& Cressey, 1974). With this increased likelihood of exposure to smoking behaviors, liaisons, as compared to members and isolates, are more likely to smoke tobacco (Roger, 1995; Valente, 1995).

\section{Isolation and ostracism}

Isolated adolescents may be more likely to smoke through two different time-ordered patterns: (a) they manage their lack of social support through smoking or (b) as pre-existing smokers they were pushed out of existing social networks. Social networks can provide the psychological and material resources needed to cope with stressors (Cohen, 2004) as well as emotional support, including feeling loved, esteemed, valued, and cared for regardless of achievement (see Bloom, Stewart, Johnston, Banks, \& Fobair, 2001 for a review). Furthermore, social support can aid in emotional regulation by limiting the intensity and duration of negative affective states (Cohen et al., 1998). Positive cognitions and emotions can reduce psychological despair and result in greater motivation to care for oneself (e.g., Cohen et al., 1998). Interestingly, the perception of available support can be more important than its use (e.g., Cohen, 2004; Bloom et al., 2001; Seeman \& Syme, 1987; Thoits, 1995). The belief that others will provide necessary resources may bolster one's perceived ability to cope with demands, thus changing an individual's assessment of a negative situation and decreasing its effective stress (see Cohen et al., 1998 for a review). Having the belief that support is at hand also may dampen the emotional and physiological responses to a stressful event or alter an individual's maladaptive behavioral responses, such as smoking or drinking (e.g., Wills \& Cleary, 1996). In previous research, adolescent isolates have reported depression and lower acceptance in comparison to members (Tani et al., 2001) and often turn to smoking to manage their negative moods (Kassel, Stroud, \& Paronis, 2003).

It is also possible that adolescent smokers have been rejected from social networks and have been pushed into isolated positions. In the past few decades, many smoking prevention programs have focused on increasing anti-smoking social norms and smoking-resistant skills and have had some success in increasing the social unacceptability of smoking tobacco (e.g., Hwang, Yeagley, \& Petosa, 2004; Thomas \& Perera, 2006). In addition, tobacco-control policies restrict adolescents from smoking and further restrict all smoking to isolated locations outside of buildings (American Nonsmokers' Rights Foundation, 2009; Coalition 
on Smoking Or Health, 1995). Thus, the enacted clean indoor air law may have forced students to smoke alone because the number of common places to smoke decreased and the vigilance on maintaining non-smoking areas increased.

\section{Arguments and findings}

An argument, then, can be made for why adolescents in one network position are more likely to smoke than adolescents in the other positions. To date, the empirical research has produced a variety of findings supporting the argument that liaisons are more likely to smoke than members and isolates (Henry \& Kobus, 2007; Kobus \& Henry, 2010), and isolates more than members and liaisons (Ennett \& Bauman, 1994) depending on their grade (Fang, Li, Stanton, \& Dong, 2003). It is clear that there are still many unanswered network questions that individual studies have failed to resolve. As a result, this paper turned to meta-analyses in an attempt to cut across studies and examine the relationship between network position and smoking behaviors among adolescents.

\section{Meta-analysis}

A meta-analysis combines the findings from different studies to test claimed (e.g., hypothesized) relationships between constructs (Hunter et al., 1982). By combining studies, these relationships are tested with a larger sample size, which leaves them less vulnerable to sampling error (Hunter \& Schmidt, 1990; Rosenthal, 1991). In addition, a meta-analysis is a formal means by which to test the consistency of the relationship across studies. A statistically significant but inconsistent relationship suggests that moderators exist. Thus, a meta-analysis provides important insights for theory and research (Hunter \& Schmidt, 1990). The following research question is tested:

RQ1: What is the relationship between adolescents' social positions-members, liaisons, or isolates—and their smoking behavior?

\section{Historical trends}

The changes in tobacco policies may have influenced the relationship between network positions and smoking behaviors among adolescents. For example, the tobacco policies may encourage smokers to develop groups: if a youth starts to smoke tobacco, he/she may find a common unregulated place to smoke. For example, approximately three-quarters of adolescent smokers reported smoking in outdoor gathering places, such as parks, storefronts, or parking lots; and about one-third of adolescent smokers reported smoking at recreation centers (Alesci, Forster, \& Blaine, 2003). Adolescent smokers may develop relationships with other teens based on this shared time together, or they may choose to select new friends based on their shared smoking behaviors or homophily (e.g., Mercken, Snijder, Steglich, \& Vries, 2009; Cohen, 1977). A second research question is posed:

RQ2: Does the association between adolescents' social positions and their smoking behaviors change over time? 


\section{Method}

\section{Studies and Procedures}

Two strategies were used to search for articles. First, all journal articles, dissertations, and book chapters were searched through computerized databases, including PsycINFO, ProQuest, and Google Scholar. Three keywords (social network, adolescent, and substance) and their synonyms, such as teen(age/ager/s) and adolescence(nts)), were entered as the search criteria. Second, tracing was used: references cited within the initial articles and those citing them were used to find other articles, dissertations, and book chapters.

The following inclusion criteria were used: Studies need to include (a) a sociometric method that required the assessment of almost all members of a network (e.g., roster in schools), (b) applicable measures of social position (group members, liaisons, and isolates) and a dependent variable of smoking behavior, and (c) a sample aged of 18 or younger. Eight different friendship networks in six studies $(N=5067)$ were included in the study (see Table 1 and 2). Even though many social network studies employed the same dataset, none of the data in the meta-analysis overlapped. The Pearson studies (Pearson \& Michell, 2000; Pearson et al., 2006) are shown twice, as there were two different data-collection periods, one for each study sample.

The studies were conducted in several countries with different students in different grades, but the percentage of females and males was almost equal across all studies. Furthermore, all studies used grade-level rosters to identify the adolescents' friendship networks, except for the Fang et al. (2003) study that used class-level roster; however, their analysis was still based on a grade-level network.

\section{Instrument and variables}

Social position-All studies in the meta-analysis except for Kobus and Henry (2010) used the software program NEGOPY (Richards, 1989; Richards \& Rice, 1981) to determine adolescents' social positions in their network. NEGOPY assigns respondents to one of three social network positions: members, liaisons, or isolates. NEGOPY defines members as people who interact with one another within one group more than they do with outside groups, which is consistent with previous research (e.g., Coleman, 1980; Dunphy, 1963). In NEGOPY, respondents were categorized as members if they had ties (direct or indirect) to at least three other members of a network who were still connected to one another after removing up to $10 \%$ of the individuals in the group. Liaisons were determined in NEGOPY when 1) individuals directly interacted with members of more than one group, or 2) individuals did not directly interact with group members but interacted with direct intermediaries. NEGOPY defines isolates as people who are minimally connected to others in a network. Respondents were categorized as isolates if they had a) no ties to other network members, (b) were members of a dyad with no other connections to the rest of the network, or (c) were connected to the rest of the network through only one tie (i.e., they would be disconnected from the network if one link is removed). Kobus and Henry (2010) used Henry's (1996) FNET program to determine three categories. The program categorized individuals as isolates if (1) they have no connections, or (2) they connected to only one 
person regardless of that person's connections; categorized individuals as members if at least three students all indicated themselves as friends, forming a triadic tie; individuals as liaisons if at least two other students are indicated as their friends, but those two other students are not friends twith each other.

Cigarette smoking-Adolescents were defined as engaging in smoking behavior based on the definitions created by the authors of the studies included in the meta-analysis.

Adolescents' smoking behaviors were self-reported in all of the studies except for one that used alveolar breath samples (Ennett \& Bauman, 1994). Definitions of smokers ranged from those who reported ever smoking (Abel, Plumridge, \& Graham, 2002; Fang et al., 2003; Pearson \& Michell, 2000; Ennett \& Bauman, 1994) to those who reported smoking regularly (Pearson et al., 2006). Adolescents were categorized as not engaging in smoking behaviors if they could not be categorized in either of the other smoking categories.

\section{Analysis Plan}

The odds ratio was used as an effect size indicator given the binary nature of the dependent variable (i.e., smoker vs. nonsmoker). When the odds ratio and standard error were reported in the articles, those were extracted directly for the meta-analysis. If such data were not included in the original articles, then other statistics (e.g., the number of smokers) that could be converted into an odds ratio were utilized. An odds ratio shows whether the ratio of the odds of an event occurring (e.g. smoking behavior) for an adolescent in an isolated network position differs from the odds of an event occurring in members by chance. An odds ratio of 1 indicates that the event is equally likely to happen or not happen.

After calculating each study' effect size, the odds ratios were weighted by the inverse of their variance and added up to produce the overall effect size. Hedges and Olkin (1985) demonstrated that this process can control for sampling error. To test the size of the weighted averaged effect, a fixed effects model was adopted since the purpose of study is to clarify the relationship between adolescents' social positions and smoking within studies instead of generalization (Hedges \& Vevea, 1998). In order to covert these data to odds ratios and main analyses, the comprehensive meta-analysis Version 2 developed by Biostat was used (Borenstein, Hedges, Higgins, \& Rithstein, 2005). Meta-regression was employed to investigate whether the studies' odd ratios related to their year of publication.

\section{Results}

\section{Network Position and Smoking}

Across studies, adolescents $(N=5067)$ were more likely to be categorized as members $(n=$ $2867)$ as compared to isolates $(n=1772)$ or liaisons $(n=428)$. For adolescents in isolated network positions, the odds of smoking are 1.55 times (CI 95\% 1.32, 1.81) as large as the odds for adolescents in group members positions and 1.49 times (CI 95\% 1.07, 2.07) as large as those in liaisons positions (see Table 2 for all odds ratios and Cohen' d). Both effect sizes are statistically significant, $z=5.35, p<.001$ and $z=2.35, p<.05$ respectively. In addition, both results are heterogeneous, $Q(7)=29.37, p<.001$ and $Q(5)=23.19, p<.001$, which indicates that moderators exist across studies. Adolescents in group members and 
liaisons positions show similar odds of smoking $(O R=1.04$, CI 95\% 0.74, 1.45), $z=0.22$, $n s$. This finding was homogenous across studies, $Q(5)=1.28, n s$, which indicates that differences between studies can be explained by sampling error. These findings answer the first research question: adolescents' positions in their social networks are related to their smoking behaviors, with isolates showing higher odds of smoking than members and liaisons, although the strength of this relationship varies across studies.

Additional Analysis-Because of comparability issues about social positions in a network across studies, analysis was re-tested after removing Kobus and Herny (2010). For isolated youths, the odds of smoking are 1.59 times (CI 95\% 1.35, 1.88) as large as the odds for youths in group members positions, $z=5.51, p<.001$ and 1.61 times (CI 95\% 1.13, 2.30 ) as large as those in liaisons positions, $z=2.61, p=0.009$. Furthermore, youths in liaisons and group members position revealed that their smoking behavior was similar to each other $(O R=1.05$, CI 95\% 0.73, 1.53, $z=0.28, p=0.78)$. In addition, Pearson et al. (2006) was eliminated and re-analyze the study ( $\mathrm{k}=6$ for group members and isolates). The re-analysis $(O R=1.56$, CI 95\% 1.22, 2.00, $z=3.53, p<.001)$ was not very different from the original analysis. Based on the additional analysis, we concluded that overall patterns did not change when maximizing comparability.

\section{Historical Trends}

To answer the second research question, a meta-regression was performed by comparing studies' odds ratios to their year of publication. The results show that the odds of adolescent smoking in isolated network positions in comparison to group members and liaisons positions decreased over time (slope $=-0.05, z=-2.44, p<.05$ and slope $=-0.11, z=$ $-3.83, p<.001$, respectively). The findings for adolescents in group members and liaisons positions are unchanged over time (slope $=0.01, z=0.47, n s$ ). These findings answer RQ2: the association between network position and smoking does change over time. The odd of smokers in isolated network positions have decreased in comparison to members and liaisons during the time when studies conducted.

\section{Discussion}

The current study examined whether and how adolescents' networks positions were related to their smoking behaviors, and whether the relationships changed over time. The sample of studies included adolescents from multiple countries over a 15 -year period. The metaanalysis showed that isolated youth were almost 1.5 times more likely to report smoking behaviors than adolescents in member positions or liaison positions, although the strength of these relationships varies across studies. There was no significant difference between the odds of smoking behaviors in liaisons and members; this finding was consistent across studies. The study also investigated date of publication, and found that the higher odds for isolates compared to members and liaisons significantly declined over time. The implications of these findings are discussed. 


\section{Isolated Smokers}

The findings have at least two implications. First, the literature on adolescent smoking focuses on peer influences, such as selection, socialization, and exposure (e.g., Botvin, Botin, Baker, Dusenbury, \& Goldberg, 1992; Chassin, Presson, Sherman, Corty, \& Olsyavsky, 1984; Fisher \& Bauman, 1988; Mercken et al., 2010). Clearly friends are not the only source for initiating smoking behaviors, since isolated adolescents showed higher odds of smoking in comparison to members and liaisons. The question of who influences isolated adolescents to smoke is important for future research. One possible influence on isolates are their siblings. Several studies have shown that when adolescents spent more time with older siblings, the adolescents were more likely to smoke and drink alcohol (Rende, Slomkowski, Lloyd-Richardson, \& Niaura, 2005; Slomkowski, Rende, Novak, Lloyd-Richardson, \& Niaura, 2005).

Next, the historical decline--that isolates' comparably higher odds of smoking (versus members liaisons) is declining over time--challenges most arguments as to why isolates are likely to smoke. First, isolates are argued to turn to smoking to manage their moods (Kassel et al., 2003, because they have less social support available to them (Tani et al., 2001). Isolated adolescents with less access to social support are more likely to be depressed (HallLande, Eisenberg, Christenson, \& Neumark-Sztanier, 2007), bored (Marcoen, Goossen, \& Caes, 1987), and lonely (Moore \& Schultz, 1983; Goswick \& Jones, 1982). Second, smokers may have been isolated due to tobacco-control policies or social rejection (e.g., Hwang et al., 2004; Thomas \& Perera, 2006). The first mechanism, mood regulation, should not change over time; the need to manage moods should be as important now as it was 15 years ago. The second, tobacco controls, should have increased the comparable odds of isolates smoking, not decreased them.

There are two possible explanations. First, isolated adolescents may be turning to other, nonstigmatized activities to manage their moods. In the United States, smokers increasingly have been thought of as unhealthy, irresponsible, dangerous deviants who pose a threat to society (Kim \& Shanahan, 2003). Instead of risking stigmatization, isolated adolescents may be turning to other activities. Second, newer and growing restrictions to particular smoking areas may have put adolescent smokers in a position to find each other more easily and to develop smoking-based, social groups. If adolescents spend time together smoking in the same location, they may perceive themselves as similar and be motivated to become friends (Engels, Knibbe, DeVries, Drop \& DeHaan, 1997; DeVries, Candel, Engels, \& Mercken, 2006).

These speculations should be tested with longitudinal data in order to have confidence in the causal dynamics of social networks and smoking behavior. A meta-analysis cannot discriminate between these two explanations, but future prevention policies and programs should investigate this issue further. Indeed, these two explanations-coping and bondingare not contradictory and could, in fact, create a circular effect such that once an adolescent starts smoking, say to deal with a stressor like isolation, he/she may be further isolated by those who object to the smoking behavior. Both influences, especially in tandem, may make it very difficult for an adolescent smoker to stop smoking without either (a) learning other mechanisms to cope with stress or (b) learning how to connect with other adolescents. Such 
arguments are supported by findings in other substance use areas; for example, Metsch et al. (1998) found that IV drug users with smaller social networks show higher rates of sharing drug equipment as a method to cope with their social isolation. As this example illustrates, social pressures sometimes outweigh physical risks (Lovell, 2002).

Isolation may also be due to other effects, such as mobility. Adolescents who move to a new school may feel more stress as they attempt to develop social relationships (Newcomb, Huba, \& Bentler, 1981; Bradshaw, Sudhinaraset, Mmari, \& Blum, 2010). It is also possible that adolescents who are isolated in their classrooms are not entirely isolated from other social networks, as they may have ties to other social networks that are not based on friendship networks in a particular school or grade (e.g., Dolcini, Harper, Susan, Catania, \& Ellen, 2005).

\section{Future Directions}

These differences have important implications for future prevention policies and programs. Other studies show that isolated adolescents are more likely to engage in delinquent behaviors, such as fighting with others and substance use, compared to connected adolescents (Farmer, \& Rodkin, 1996; Gest, Graham-Bermann, \& Hartup, 2001). These observations could be used to argue that prevention programs should aim to find isolated youth and help them connect with their larger social networks. Unfortunately, few networkbased interventions, such as changing a person's position from isolated to integrated, have been rigorously studied, and those that have undertaken such endeavors have shown mixed results (Cutrona \& Cole, 2000). In addition, if isolated youth maintain non-school-based relationships, then it is not their isolation but their networks that may be problematic. Finally, current prevention programs focusing on a peer-pressure model of smoking adoption may not benefit isolated adolescent smokers. At minimum, the findings suggest that prevention programs targeting isolated adolescents may be needed.

\section{Limitations}

This study has limitations. First, the sample of studies included in the meta-analysis was too small to test additional moderators of the relationship between network position and smoking. Cultures/location and grades were possible moderators to be considered. However, in order to find conclusive moderators, the more number of studies will be required. For example, locations or culture may provide different social pressure on smoking behavior for youths. Second, the definitions of smoking behavior differ between studies (e.g., smoking onset and rates of progression), which may be one of the moderators in the meta-analytic relationships. Although the ever-smokers (e.g., quitter, experimenter) are different from current smokers in terms of characteristics, in our study, there was only one study to use current smoking measurement. Thus, the more study will be required in order to show how smoking status are associated with social positions in a network. In addition, except for one study (Kobus \& Henry, 2010), the definitions of social positions were the same. Even though some studies were removed for comparability and re-analyzed it, the findings would not change. This consistency benefits our ability to draw meta-analytic conclusions about members, isolates, and liaisons, but it limits our ability to generalize the findings to other definitions of these network positions. 


\section{Conclusion}

This study has unique and important contributions to theory and practice. The meta-analytic results showed that adolescents from multiple countries who are isolated in friendship networks are more likely to report smoking behaviors than those with friends (members or liaisons), although this relationship varies across studies and has decreased over a 15-year period. There is a robust relationship between friendship and smoking behaviors in adolescence. The task for prevention theory and practice is to understand how adolescents without friends in school pick up smoking behaviors, why isolation may be less relevant in recent years, and how to prevent smoking behaviors in this changing environment.

\section{Acknowledgments}

Declaration of Interest

This project was supported by Award Number P50-DA010075 and R01-DA021670 from the National Institute on Drug Abuse. The content is solely the responsibility of the authors and does not necessarily represent the official views of the National Institute on Drug Abuse or the National Institutes of Health.

\section{References}

Abel G, Plumridge L, Graham P. Peer, networks or relationships: Strategies for understanding social dynamics as determinants of smoking behavior. Drugs: Education, Prevention and Policy. 2002; 9:325-338.

Alesci NL, Forster JL, Blaine TB. Smoking visibility, perceived acceptability, and frequency in various locations among youth and adults. Preventive Medicine. 2003; 36:272-281. [PubMed: 12634018]

Alexander C, Piazza M, Mekos D, Valente TW. Peer networks and adolescent cigarette smoking: An analysis of the national longitudinal study of adolescent health. Journal of Adolescent Health. 2001; 29:22-30. [PubMed: 11429302]

Aloise-Young P, Graham JW, Hansen WB. Peer influence on smoking initiation during early adolescence: A comparison of group members and group outsiders. Journal of Applied Psychology. 1994; 79:281-287. [PubMed: 8206817]

American Nonsmokers' Rights Foundation. Overview list - how many smokefree laws? Retrieved October. 2009; 27:2010. from the http://www.no-smoke.org/pdf/mediaordlist.pdf.

Arnett JJ. Adolescent storm and stress, reconsidered. American Psychologist. 1999; 54:317-326. [PubMed: 10354802]

Bloom JR, Stewart SL, Johnston M, Banks P, Fobair P. Sources of support and the physical and mental well-being of young women with breast cancer. Social Science \& Medicine. 2001; 53:1513-24. [PubMed: 11710426]

Borenstein, M.; Hedges, L.; Higgins, J.; Rothstein, H. Comprehensive meta-analysis, version 2. Biostat Inc.; Englewood, New Jersey: 2005.

Botvin GJ, Backer E, Botvin EM, Dusenbury L, Cardwell J, Diaz T. Factors promoting cigarette smoking among black youth: A causal modeling approach. Addictive Behaviors. 1993; 18:397-405. [PubMed: 8213293]

Botvin GJ, Botvin EM, Baker E, Dusenbury L, Goldberg CJ. The false consensus effect: Predicting adolescents' tobacco use from normative expectations. Psychological Reports. 1992; 70:171-178. [PubMed: 1565717]

Bradshaw CP, Sudhinaraset M, Mmari K, Blum RW. School transitions among military adolescents: A qualitative study of stress and coping. School Psychology Review. 2010; 39:84-105.

Bryant AL, Schulenberg J, Bachman JG, O'Malley PM, Johnson LD. Understanding the links among school misbehavior, academic achievement, and cigarette use: A national panel study of adolescents. Prevention Science. 2000; 1:71-87. [PubMed: 11521961] 
Buunk BP, Hoorens V. Social support and stress: the role of social comparison and social exchange processes. British Journal of Clinical Psychology. 1992; 31:445-457. [PubMed: 1483155]

Chassin L, Presson CC, Rose JS, Sherman SJ. The natural history of cigarette smoking from adolescence to adulthood: Demographic predictors of continuity and change. Health Psychology. 1996; 15:478-484. [PubMed: 8973929]

Chassin L, Presson C, Sherman S, Corty E, Olsyavsky R. Predicting the onset of cigarette smoking in adolescents: A longitudinal study. Journal of Applied Social Psychology. 1984; 14:224-243.

Coalition on Smoking or Health (CSOH). State legislative actions on tobacco issues. Coalition on Smoking or Health; Washington, DC: 1995.

Cohen JM. Sources of peer group homogeneity. Sociology of Education. 1977; 50:227-241.

Cohen S. Social relationships and health. American Psychologist. 2004; 59:676-684. [PubMed: 15554821]

Cohen S, Frank E, Doyle WJ, Skoner DP, Rabin BS, Gwaltney JM Jr. Types of stressors that increase susceptibility to the common cold in adults. Health Psychology. 1998; 17:214-223. [PubMed: 9619470]

Colby SM, Tiffany ST, Shiffman S, Niaura RS. Are adolescent smokers dependent on nicotine? A review of the evidence. Drug and Alcohol Dependence. 2000; 59:S83-S95. [PubMed: 10773439]

Coleman, JC. Friendship and the peer group in adolescence.. In: Adelson, J., editor. Handbook of adolescent psychology. Wiley; New York: 1980. p. 408-431.

Conrad KM, Flay BR, Hill D. Why children start smoking cigarettes: Predictors of onset. British Journal of Addiction. 1992; 87:1711-1724. [PubMed: 1490085]

Cutrona, CE.; Cole, V. Optimizing support in the natural network.. In: Cohen, S.; Underwood, LG.; Gottlieb, BH., editors. Social support measurement and intervention: A guide for health and social scientists. Oxford University Press; New York: 2000. p. 278-308.

De Vries H, Candel M, Engels R, Mercken L. Challenges to the peer influence paradigm: Results for 12-13 year olds from six European countries from the European smoking prevention framework approach study. Tobacco Control. 2006; 15:83-89. [PubMed: 16565454]

Dolcini MM, Harper GW, Susan EW, Catania JA, Ellen JM. Friends in the 'hood: Should peer-based health promotion programs target nonschool friendship networks? Journal of Adolescent Health. 2005; 36:267.e6-267.e15. [PubMed: 15737785]

Dunphy DC. The social structure of urban adolescent peer groups. Sociometry. 1963; 26:230-246.

Eder D. The cycle of popularity: Interpersonal relations among female adolescents. Sociology of Education. 1985; 58:154-165.

Eiser C, Walsh S, Eiser JR. Young children's understanding of smoking. Addictive Behaviors. 1986; 11:119-123. [PubMed: 3739797]

Engels RCME, Knibbe RA, De Vries H, Drop MJ, de Haan YT. Homogeneity of cigarette smoking within peer groups: Influence or selection? Health Education \& Behavior. 1997; 24:801-811. [PubMed: 9408792]

Ennett ST, Bauman KE. The contribution of influence and selection to adolescent peer group homogeneity: The case of adolescent cigarette smoking. Journal of Personality and Social Psychology. 1994; 67:653-663. [PubMed: 7965611]

Ezzati M, Lopez AD. Estimates of global mortality attributable to smoking in 2000. Lancet. 2000; 362:847-852. [PubMed: 13678970]

Fang X, Li X, Stanton B, Dong Q. Social network positions and smoking experimentation among Chinese adolescents. American Journal of Health Behavior. 2003; 27:257-267. [PubMed: 12751622]

Farmer TW, Rodkin PC. Antisocial and prosocial correlates of classroom social positions: The social network centrality perspective. Social Development. 1996; 5:174-188.

Fisher LA, Bauman KE. Influence and selection in the friend-adolescent relationship: Findings from studies of adolescent smoking and drinking. Journal of Applied Social Psychology. 1988; 18:289_ 314.

Flay BR, Hu FB, Richardson J. Psychosocial predictors of different stages of cigarette smoking among high school students. Preventive Medicine. 1998; 27:A9-A18. [PubMed: 9808813] 
Flay BR, Hu FB, Siddiqui O, Day LE, Hedecker D, Petraitis J, et al. Differential influence of parental smoking and friends' smoking on adolescent initiation and escalation of smoking. Journal of Health and Social Behavior. 1994; 35:248-265. [PubMed: 7983337]

Friedman LS, Lichtenstein E, Biglan A. Smoking onset among teens: An empirical analysis of initial situations. Journal of Adolescent Health. 1985; 10:1-13.

Gervais A, O'Loughlin J, Meshefedjian G, Bancej C, Tremblay M. Milestones in the natural course of onset of cigarette use among adolescents. Canadian Medical Association Journal. 2006; 175:255261. [PubMed: 16880445]

Gest SD, Graham-Bermann SA, Hartup WW. Peer experience: Common and unique features of number of friendships, social network centrality, and sociometric status. Social Development. 2001; 10:23-40.

Goffman, E. The presentation of self in everyday life. Anchor/Doubleday; Garden City, NY: 1959.

Goswick IRA, Jones WH. Components of loneliness during adolescence. Journal of Youth and Adolescence. 1982; 11:373-383. [PubMed: 24310911]

Hall-Lande JA, Eisenberg ME, Christenson SL, Neumark-Sztanier D. Social isolation, psychological health, and protective factors in adolescence. Adolescence. 2007; 42:265-286. [PubMed: 17849936]

Hartup WW. Social relationships and their developmental significance. American Psychologist. 1989; 44:120-126.

Hedges, LV.; Olkin, I. Statistical methods for meta-analysis. Academic Press; New York: 1985.

Hedges LV, Vevea JL. Fixed- and random-effect models in meta-analysis. Psychological Methods. 1998; 3:486-504.

Henry, DB. FNET: A computer program for social network analysis of peer nomination data (Technical report). University of Illinois at Chicago, Institute for Juvenile Research; Chicago: 1996.

Henry DB, Kobus K. Early adolescent social networks and substance use. Journal of Early Adolescence. 2007; 27:346-362.

Hirschi, T. Causes of delinquency. University of California Press; Berkeley, CA: 1969.

Hunter, JE.; Schmidt, FL. Methods of meta-analysis. Sage; Newbury Park, CA: 1990.

Hunter, JE.; Schmidt, FL.; Jackson, GB. Meta-analysis: Cumulating research findings across studies. Sage; Beverly Hills, CA: 1982.

Hwang MS, Yeagley KL, Petosa R. A meta-analysis of adolescent psychosocial smoking prevention programs published between 1987 and 1997 in the United States. Health Education \& Behavior. 2004; 31:702-719. [PubMed: 15539543]

Ikard FF, Green PE, Horn D. A scale to differentiate between types of smoking as related to the management of affect. International Journal of the Addictions. 1969; 4:649-659.

Kassel JD, Stroud LR, Paronis CA. Smoking, stress, and negative affect: Correlation, causation, and context across stages of smoking. Psychological Bulletin. 2003; 129:270-304. [PubMed: 12696841]

Kim S, Shanahan J. Stigmatizing smokers: Public sentiment toward cigarette smoking and its relationship to smoking behaviors. Journal of Health Communication. 2003; 8:343-367. [PubMed: 12907400]

Kobus K, Henry DB. Interpaly of network position and peer substance use in early adolescent cigarette, alcohol and marijuana use. Journal of Early Adolescence. 2010; 30:225-245.

Lovell AM. Risking risk: The influence of types of capital and social networks on the injection practices of drug users. Social Science \& Medicine. 2002; 55:803-821. [PubMed: 12190272]

Marcoen A, Goossens L, Caes P. Loneliness in pre- through late adolescence: Exploring the contributions of a multidimensional approach. Journal of Youth and Adolescence. 1987; 16:561577. [PubMed: 24277491]

Mercken L, Snijder TAB, Steglich C, de Vries H. Dynamics of adolescent friendship networks and smoking behavior: social network analyses in six European countries. Social Science \& Medicine. 2009; 69:1506-1514. [PubMed: 19775794] 
Mercken L, Snijders TAB, Steglich C, Vertiainen E, de Vries H. Smoking-based selection and influence in gender-segregated friendship networks: A social network analysis of adolescent smoking. Addition. 2010; 105:1280-1289.

Metsch LR, McCoy CB, McCoy HV, Shultz J, Inciardi J, Wolfe H, Correa R. Social influences: living arrangements of drug using women at risk for HIV infection. Women Health. 1998; 27:123-36. [PubMed: 9640638]

Michell L. Loud, sad or bad: Young people's perceptions of peer groups and smoking. Health Education Research. 1997; 11:39-49.

Michell L, Amos A. Girls, pecking order and smoking. Social Science \& Medicine. 1997; 44:18611869. [PubMed: 9194247]

Moore D, Schultz NR. Loneliness at adolescence: Correlates, attributions, and coping. Journal of Youth and Adolescence. 1983; 12:95-100. [PubMed: 24306225]

Newcomb MD, Huba GJ, Bentler PM. A multidimensional assessment of stressful life events among adolescents: Derivation and correlates. Journal of Health and Social Behavior. 1981; 22:400-415.

Nichter M, Nichter M, Vuckovic N, Quintero G, Ritenbaugh C. Smoking experimentation and initiation among adolescent girls: Qualitative and quantitative findings. Tobacco Control. 1997; 6:285-295. [PubMed: 9583626]

Oetting ER, Beauvais F. Peer cluster theory: Drugs and the adolescent. Journal of Counseling Psychology. 1986; 34:205-213.

Oetting ER, Deffenbacher JL, Donnermeyer JF. Primary socialization theory: The role played by personal trait in the etiology of drug use and deviance. Substance Use and Misuse. 1998; 33:13371366. [PubMed: 9603274]

Oetting ER, Donnermeyer JF. Primary socialization theory: The etiology of drug use and deviance. Substance Use and Misuse. 1998; 33:995-1026. [PubMed: 9548633]

Pearson M, Michell L. Smoke rings: Social network analysis of friendship groups, smoking and drugtaking. Drugs: Education, Prevention and Policy. 2000; 7:21-37.

Pearson M, Sweeting H, West P, Young R, Gordon J, Turner K. Adolescent substance use in different social and peer contexts: A social network analysis. Drugs: Education, Prevention and Policy. 2006; 13:519-536.

Rende R, Slomkowski C, Lloyd-Richardson E, Niaura R. Sibling effects on substance use in adolescence: Social and genetic relatedness. Journal of Family Psychology. 2005; 19:611-618. [PubMed: 16402876]

Petronio, S. The boundaries of privacy: Praxis of everyday life.. In: Petronio, S., editor. Balancing the secrets of private disclosures. Lawrence Erlbaum; Mahwah, NJ: 2000. p. 37-49.

Richards, WD. The NEGOPY network analysis program. Department of Communications, Simon Fraser University; Burnaby, British Columbia, Canada: 1989.

Richards WD, Rice RE. The NEGOPY network analysis program. Social Networks. 1981; 3:215-223.

Roger, EM. Diffusion of innovation. 4th ed.. Free Press; New York: 1995.

Rosenthal, R. Meta-analytic procedures for social research. Sage; Newbury Park, CA: 1991.

Schaefer C, Coyne JC, Lazarus RS. The health-related functions of social support. Journal of Behavioral Medicine. 1981; 4:381-406. [PubMed: 7338894]

Seeman TE, Syme SL. Social networks and coronary artery disease: A comparison of the structure and function of social relations as predictors of disease. Psychosomatic Medicine. 1987; 49:341-354. [PubMed: 3615763]

Slomkowski C, Rende R, Novak S, Lloyd-Richardson E, Niaura R. Sibling effects on smoking in adolescence: Evidence for social influence from a genetically informative design. Addiction. 2005; 100:430-438. [PubMed: 15784052]

Sutherland, EH.; Cressey, DR. Criminology. 9th ed.. Lippincott; Philadephia, PA: 1974.

Tani CR, Chavez EL, Deffenbacher JL. Peer isolation and drug use among white non-Hispanic and Mexican American adolescents. Adolescence. 2001; 36:127-139. [PubMed: 11407629]

Thoits PA. Stress, coping, and social support processes: Where are we? What next? Journal of Health and Social Behavior, Extra Issue. 1995:53-79. 
Thomas RE, Perera R. School-based programmes for preventing smoking. Cochrane Database of Systematic Reviews. 2006; 3:1-163.

Tucker JS, Martínez JF, Ellickson PL, Edelen MO. Temporal associations of cigarette smoking with social influences, academic performance, and delinquency: A four-wave longitudinal study from ages 13-23. Psychology of Addictive Behaviors. 2008; 22:1-11. [PubMed: 18298226]

Unger JB, Chen X. The role of social networks and media receptivity in predicting age of smoking initiation: A proportional hazards model of risk and protective factors. Addictive Behaviors. 1999; 24:371-381. [PubMed: 10400276]

Urberg KA, Degirmencioglu SM, Pilgrim C. Close friend and group influence on adolescent cigarette smoking and alcohol use. Developmental Psychology. 1997; 33:834-844. [PubMed: 9300216]

Valente, TW. Network models of the diffusion of innovations. Hampton Press; Cresskill, NJ: 1995.

Valente TW, Unger JB, Johnson AC. Do popular students smoke? The association between popularity and smoking middle school students. Journal of Adolescent Health. 2005; 37:323-329. [PubMed: 16182143]

Wang MQ, Fitzhugh EC, Eddy JM, Fu Q, Turner LW. Social influences on adolescents'smoking progress: A longitudinal analysis. American Journal of Health Behavior. 1997; 21:111-117.

Warren CW, Jones NR, Eriksen MP, Asma S. Patterns of global tobacco use in young people and implications for future chronic disease burden in adults. Lancet. 2006; 367:749-753. [PubMed: 16517275]

Wasserman, S.; Faust, K. Social network analysis: Methods and applications. Cambridge University Press; Cambridge, UK: 1994.

Wiatrowski MD, Griswold DB, Roberts MK. Social control theory and delinquency. American Sociological Review. 1981; 46:525-541.

Wills TA, Cleary SD. How are social support effects mediated: A test for parental support and adolescent substance use. Journal of Personality and Social Psychology. 1996; 71:937-952. [PubMed: 8939042] 


\section{Odds ratio and $95 \% \mathrm{CI}$}

\begin{tabular}{l|l|l|l|l|}
\hline Abel & & & & \\
Fang6 & & & & \\
Fang8 & & & & \\
Fang10 & & & & \\
Pearson (2000) \\
Pearson (2006) \\
Ennett \\
Kobus \\
Fixed model
\end{tabular}

Figure 1.

Odds ratio and 95\% Confidential Interval for group members vs. Isolates Note. The size of box represents relative weighted values each study. 


\section{Study name Odds ratio and 95\% CI}

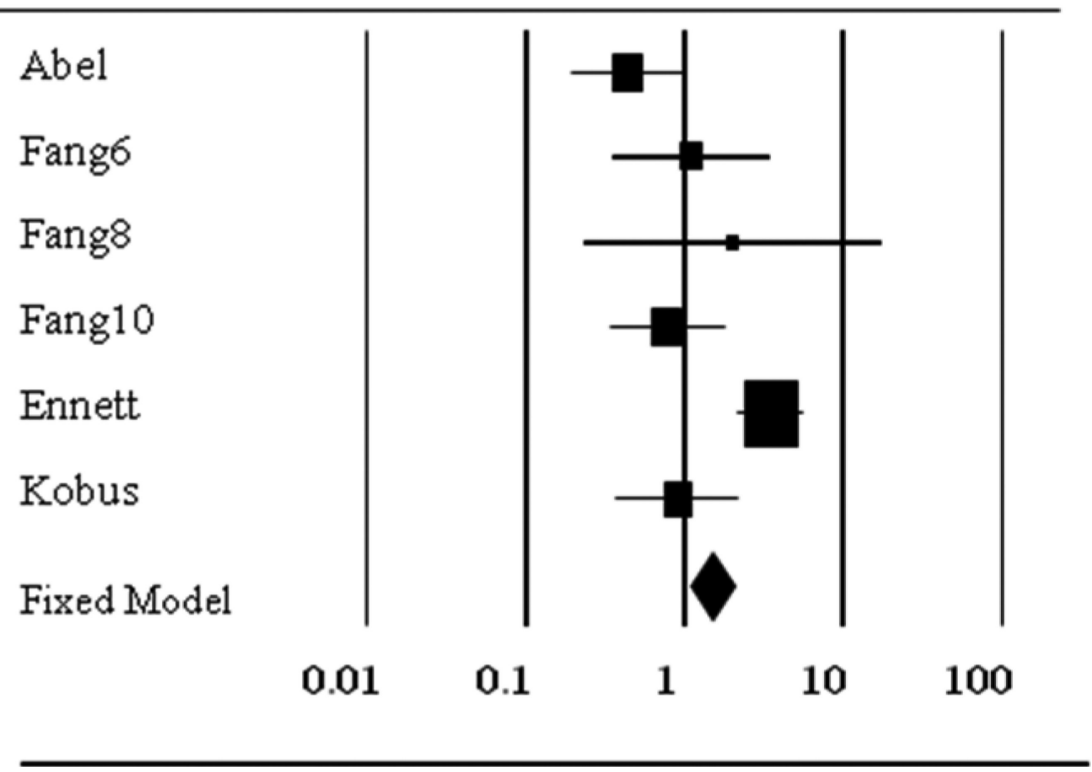

Figure 2.

Odds ratio and 95\% Confidential Interval for Liaison vs. Isolates

Note. The size of box represents relative weighted values each study. 


\section{Table 1}

Descriptive Statistics of Studies in Meta-Analysis

\begin{tabular}{lccccc}
\hline Author & Year & Grade & Mean Age & \% Female & Location \\
\hline Abel & 2002 & 10 & NR & NR & New Zealand \\
Fang & 2003 & 6 & 11.60 & 43 & China \\
Fang & 2003 & 8 & 13.74 & 58 & China \\
Fang & 2003 & 10 & 15.71 & 45 & China \\
Pearson & 2000 & S2 & NR & 43.3 & Scotland \\
Pearson & 2006 & S2 / S4 & NR & 50 & Scotland \\
Ennett & 1994 & 9 & 14.1 & 50 & United States \\
Kobus & 2010 & $6-8$ & NR & 48.5 & United States \\
\hline
\end{tabular}

Note. $\mathrm{NR}=$ not reported. 


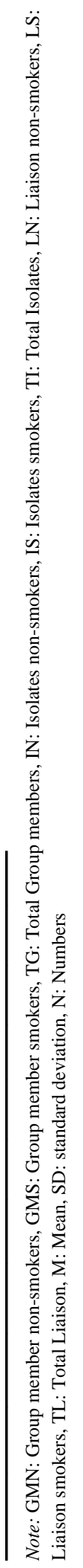




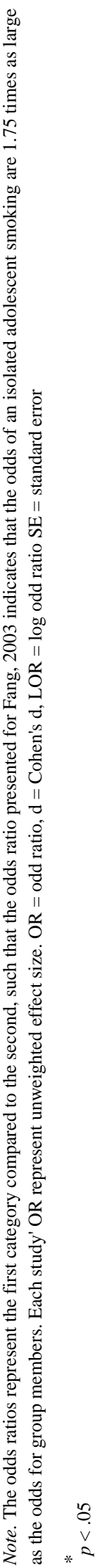

